\title{
Anti-Proliferative Activity of Benzamide Analogs in A549 Tumor Cells in Vitro
}

\section{Li-wen SHEN ${ }^{1}$, Yan-ling WU ${ }^{2, a, *}$, Min $\mathrm{CHEN}^{2}$, Yoshimasa Tanaka ${ }^{3}$ and Wen $\mathrm{ZHANG}^{1 *}$}

${ }^{1}$ Department of Biopharmaceutical Sciences, College of Pharmaceutical Sciences, Zhejiang University of Technology, 18 Chaowang Road, Hangzhou, 310014, China

${ }^{2}$ Virus Inspection Department of Zhejiang Provincial Center for Disease Control and Prevention, 3399 Binsheng Road, Hangzhou, 310051, China

${ }^{3}$ Center for Innovation in Immunoregulative Technology and Therapeutics, Graduate School of Medicine, Kyoto University, Kyoto, 606-8501, Japan

\author{
aylwu@cdc.zj.cn. \\ ${ }^{*}$ Corresponding author
}

Keywords: Anti-Proliferative, Benzamide Analogs, A549, RTCA.

\begin{abstract}
Objective: To determine the antitumor activity of five benzamide derivatives with similar structure in A549 tumor cells. Methods: Cytotoxicity of the compounds in A549 tumor cells were monitored through an xCELLigence Real-Time Cell Analysis System. Results: Four benzamide analogs inhibited the growth of A549 tumor cells in a dose- and time-dependent manner. Conclusion: Four benzamide derivatives exhibited antiproliferative activity against A549 tumor cells in vitro and could be further developed in preclinical studies as therapeutic agents for non small cell lung cancer.
\end{abstract}

\section{Introduction}

Lung cancer is one of the most serious threats to human health [1]. Recent reports from many countries revealed that the incidence and mortality rates of lung cancer account for the first and second of all malignant tumors in male and female, respectively [2-4]. Non-small cell lung cancer (NSCLC) is the most common lung cancer and accounts for approximately $80 \%$ of the total lung cancer. NSCLC is less sensitive to conventional chemotherapy than other types, and its 5-year survival rate is as low as only $15 \%[5,6]$. Hence, it is urgent to develop novel therapeutics for NSCLC treatment.

Histone deacetylases (HDACs) are a class of proteases which play an important role in the structural modification of chromosome and the regulation of gene expression. Histone acetylation facilitates the dissociation of DNA and histone octamer and relaxes the nucleosome structure, which allows transcription factors and co-transcription factors to bind specific sites in DNA, resulting in the promotion of genes transcription. In tumor cells, over expression of HDACs would lead to enhanced deacetylation and increase the affinity between DNA and histones, which makes slack nucleosomes become very tight and down-regulates the expression of particular genes, especially some tumor suppressor genes. The close relation between deregulated HDACs expression and tumor highlight them as attractive targets for tumor therapies [7].

Histone deacetylase inhibitors (HDACi) increase histone acetylation, thereby regulate the expression of related genes and induce apoptosis and differentiation in 
tumor cells. Since the advantages of relatively high selectivity and low toxicity, HDACi have attracted much attention from Drug R \& D personnel as a class of potential anticancer drugs [8-10]. Benzamide compounds represent a novel class of HDACi which show inhibitory activity through binding to a hydrophobic pocket of the center region of the HDAC catalytic site $[11,12]$. To date, two benzamide analogs MS-275 and MGCD0103 have entered clinical trials and shown promising results [13, 14]. Based on these results, we examined five benzamide analogs for antiproliferative activity in A549 tumor cells to search for valuable lead compounds for NSCLC treatment.

\section{Materials and methods}

\section{Materials}

Benzamide analogs (2A, 2B, 2C, 2D, and 2E) were obtained from College of Pharmacy, Zhejiang University of Technology, China. The compounds were provided in a powdery form and dissolved in DMSO, which was further diluted with RPMI1640 medium. For the analysis of tumor growth, Real-Time Cell Analyzer (RTCA) System (Roche) was utilized. RPMI1640 medium, fetal bovine serum (FBS), and penicillin/streptomycin were purchased from Life Technology; A549 tumor cell line (non small cell lung cancer) from American Type Culture Collection (ATCC).

\section{Methods}

\section{Cytotoxicity assay using an RTCA system}

Cytotoxicity assay was performed using a modified method as described in our previous report [15]. To obtain background levels, $95 \mu \mathrm{L}$ of RPMI1640 medium were added to each well of 96-Plate first, followed by $100 \mu \mathrm{L}$ of cell suspensions containing about 8,000 A549 tumor cells. Approximately $24 \mathrm{~h}$ after incubation, when the cells reached exponential growth phase, $5 \mu \mathrm{L}$ of benzamide analogs $(2 \mathrm{~A}, 2 \mathrm{~B}, 2 \mathrm{C}$, $2 \mathrm{D}$, and 2E) were added to each well at final concentrations of 10, 30, 60, 90, and 120 $\mu \mathrm{M}$, respectively. Solvent control (1\% DMSO) and blank control were also included. To monitor the viability of the cells in each well, impedance was automatically recorded every $15 \mathrm{~min}$ by the Real-Time Cell Analyzer System. All operation processes were performed in a humidified atmosphere at $37^{\circ} \mathrm{C}$ with $5 \% \mathrm{CO}_{2}$.

\section{Statistics.}

All experiments were performed in triplicate. Data were presented as mean \pm SD and percentage. Data were evaluated by t-test and one-way Analysis of Variance and $p<$ 0.05 were considered significant.

\section{Results and Discussion}

RTCA measurement showed that cell survival rates were significantly decreased when A549 tumor cells were exposed to various concentrations of benzamide analogs for $24 \mathrm{~h}$, compared to controls. Compounds $2 \mathrm{~A}(p=0.0067), 2 \mathrm{C}(p<0.0001), 2 \mathrm{D}$ ( $p$ $=0.0002)$ and $2 \mathrm{E}(p=0.0416)$ markedly inhibited the proliferation of A549 cells in a time- and dose-dependent manner (Figure1 and Table1). However, compound 2B did not inhibit the proliferation of the tumor cells effectively even at the highest concentration, $120 \mu \mathrm{M}$, used in this study, the $p$ value is 0.4091 . The results revealed that structurally distinct benzamide analogs $(2 \mathrm{~A}, 2 \mathrm{C}, 2 \mathrm{D}$, and $2 \mathrm{E})$ suppressed the proliferation of A549 tumor cells to different degrees. 
Table 1 . Cytotoxicity elicited by various concentrations of compounds $2 \mathrm{~A}-2 \mathrm{E}$

\begin{tabular}{llllll}
\hline & \multicolumn{5}{c}{ AUC-24 } \\
\hline Compound $(\mu \mathrm{M})$ & $2 \mathrm{~A}$ & $2 \mathrm{~B}$ & $2 \mathrm{C}$ & $2 \mathrm{D}$ & $2 \mathrm{E}$ \\
Control & 63.0 & 62.8 & 65.3 & 81.5 & 62.5 \\
DMSO & 62.6 & 63.0 & 60.2 & 77.9 & 56.3 \\
10 & 54.0 & 52.0 & 52.0 & 71.5 & 46.8 \\
30 & 43.1 & 46.9 & 48.7 & 62.0 & 40.2 \\
60 & 36.4 & 46.0 & 47.6 & 54.1 & 39.6 \\
90 & 35.0 & 42.3 & 36.0 & 32.7 & 33.0 \\
120 & 30.8 & 41.5 & 27.7 & 26.4 & 32.2 \\
\hline
\end{tabular}

AUC-24: Area under concentration-time curve $24 \mathrm{~h}$ after the addition of the compound

The IC50 values of the compound 2A-2E for A549 cells were obtained by using an xCELLigence System software (Figure 2). The five benzamide analogs inhibited the growth of A549 tumor cells to different degrees in the following order; compound 2D > compound $2 \mathrm{C}>$ compound $2 \mathrm{~A}>$ compound $2 \mathrm{E}>$ compound $2 \mathrm{~B}$. Compounds $2 \mathrm{C}$ and 2D showed superior cytotoxicity to A549 cells with the IC50 of 11.5 and $8.4 \mu \mathrm{M}$, respectively, whereas compound $2 \mathrm{~B}$ displayed a weak killing effect against A549 tumor cells. It is evident that there was a dichotomy in IC50 for A549 cells between compounds $2 \mathrm{~B}$ and $2 \mathrm{D}$, suggesting that subtle changes in structure of the benzamide analogs might cause significant difference in the inhibitory activity for A549 tumor cells.

Figure. 1. Effect of benzamide analogs $2 \mathrm{~A}-2 \mathrm{E}$ on the proliferation of A549 tumor cells when

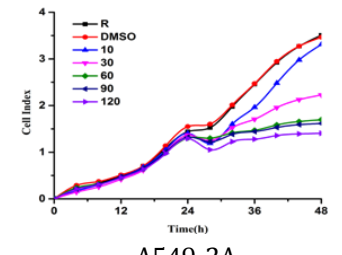

A549-2A

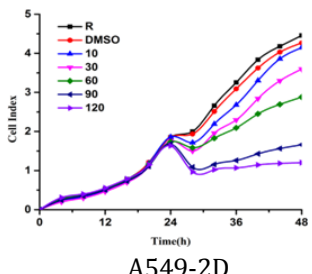

A549-2D

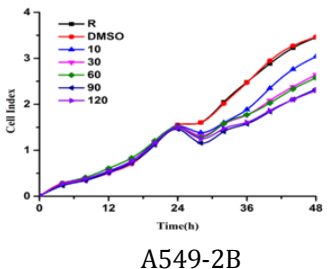

A549-2B

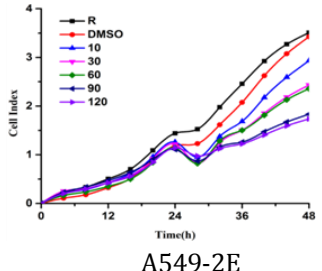

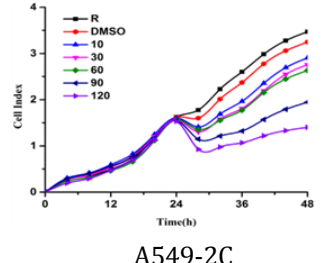

A549-2C

determined through an RTCA system. Cell Index: Relative cell number; R: neither compounds or DMSO is added; DMSO: $1 \%$ DMSO is added to cell; $10: 10 \mu \mathrm{M}$ compound is added to cell; $30: 30 \mu \mathrm{M}$ compound is added to cell; 60: $60 \mu \mathrm{M}$ compound is added to cell; $90: 90 \mu \mathrm{M}$ compound was added to

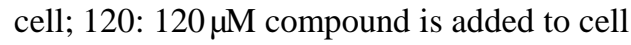




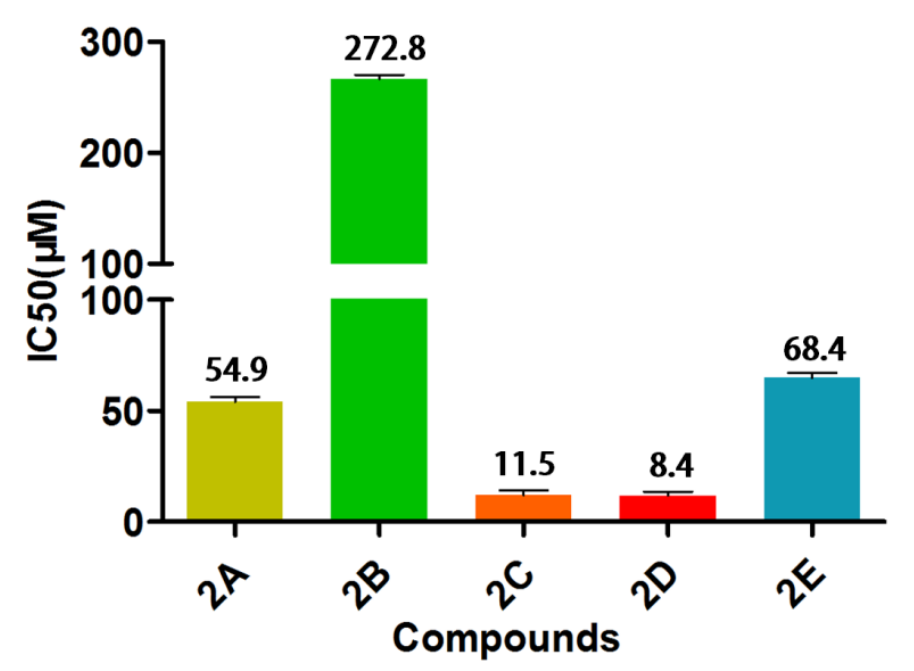

Figure.2. The IC50 of the compounds 2A-2E for A549 cells. IC50: half maximal inhibitory

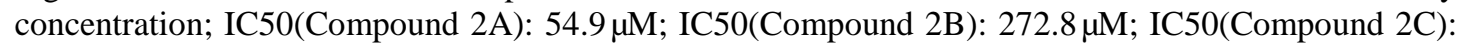
11.5 $\mu \mathrm{M}$; IC50(Compound 2D): 8.4 $\mu \mathrm{M}$; IC50(Compound 2E): $68.4 \mu \mathrm{M}$

\section{Conclusion}

Benzamide derivatives have recently received considerable attention because of their HDACi properties. All the five benzamide analogs except $2 \mathrm{~B}$ examined in this study showed a potent inhibitory activity against A549 cells in a concentration- and time-dependent manner. Of the five analogs, compound 2D is the most effective against A549 cells. Our findings demonstrated that these benzamide compounds were potent HDACs inhibitors and could be promising candidates for further development of chemotherapeutic drugs for lung cancer. The antitumor activity elicited by these compounds may be attributed to their inhibitory activity against HDACs. In order to develop medicines for lung cancer, it is cardinal to further extend the investigation of drugs for lung cancer and elucidate the mechanism by which the benzamide derivatives efficiently inhibited the proliferation of lung cancer.

\section{Acknowledgments}

We gratefully acknowledge the support by the Natural Science Foundation of China (21442008), International S\&T Cooperation Program of China (2015DFG32530), Natural Science Foundation of Zhejiang province (LY16H160003), the Key program co-founded by Zhejiang province and the Ministry of Health (2017192349), the Program for Zhejiang Leading Team of Science and Technology Innovation (2011R50021), and National High Technology Research and Development Program of China (863 Program) (2014AA06A514).

\section{References}

[1] Zhang W, Lei P, Dong Xe et al. Drug Des Devel Ther. 2014; 6(8): 735-744.

[2] Henley SJ, Richards TB, Underwood JM et al. MMWR Morb Mortal Wkly Rep. 2014; 63(1): 1-5.

[3] Chen W, Zheng R, Zhang S et al. Chin J Cancer. 2013; 32(3): 106-12. 
[4] Zatonski WA1, Manczuk M, Powles J et al. Eur J Public Health. 2007; 17(5): 450-4.

[5] Yano S, Matsumori Y, Ikuta K et al. Int J Clin Oncol. 2006; 11(2): 73-81.

[6] D'Addario G, Pintilie M, Leighl NB et al. J Clin Oncol. 2005; 23(13): 2926-36.

[7] De Ruijter AJ, van Gennip AH, Caron HN et al. Biochem J. 2003; 370(3): 737-49.

[8] Whittle N, Singewald N. Biochem Soc Trans. 2014; 42(2): 569-81.

[9] Bolden JE, Shi W, Jankowski K et al. 2013; 28(4): e519.

[10]Chen F, Chai H, Su MB et al. ACS Med Chem Lett. 2014 Apr 4; 5(6): 628-33.

[11] Shan B, Xu C, Zhang Y et al. J Proteome Res. 2014 Jun 16. [Epub ahead of print]

[12] Blackburn C1, Barrett C, Chin J et al. J Med Chem. 2013; 56(18): 7201-11.

[13] Yardley DA, Ismail-Khan RR, Melichar B et al. J Clin Oncol. 2013; 31(17): 2128-35.

[14]Blum KA, Advani A, Fernandez L et al. Br J Haematol. 2009; 147(4): 507-14.

[15]Wu YL, Shen LW, Zhang W. Advanced Materials Research. 2014; 908: 220-223. 